\title{
The surgical procedure of syringomyelie with Chiari I in adults regarding the intrapial aspiration of cerebellar tonsils: does this procedure improve symptoms with less complication?
}

\author{
Ait Bachir Mustapha ${ }^{1,2}$, T. Benbouzid ${ }^{1,2}$ \\ 1 Department of Neurosurgery, Nedir Mohamed Hospital, \\ Tizi Ouzou, AlgERIA \\ 2 Department of Neurosurgery, Bab el Oued Hospital, ALGERIA
}

\section{ABSTRACT}

Introduction. Cranio-vertebral decompression remains the common denominator for the treatment of syringomyelia associated with Chiari I. On the other hand, the details of the procedure, remains controversial. The success of the surgery is to restore the circulation of cerebro-spinal fluid at the level of the foramen magnum. How is this circulation restored to the level of foramen is the question? We offer our attitude towards the treatment of syringomyelia with Chiaril.

Material and method. Consecutive series of 32/121 patients benefiting from craniovertebral decompression associated with intrapial aspiration of cerebellar tonsils treated for syringomyelia with a Chiari I malformation in adults.

Result. Motor deficits were present in 20 / 22 patients, representing $90 \%$ of the entire patient group. these motor deficits are improved in 16 out of 22 cases, and remained unchanged in 06cas. no motor aggravation occurred. in our study, bone decompression and intra pial aspiration of cerebellar tonsils (sub arachnoids manipulation) were found to be associated with favourable results on clinical signs and symptoms. However, sub arachnoids manipulation and intra pial aspiration of cerebellar tonsils showed a little more complication compared with bone decompression with dural plasty.

Conclusion. The bone decompression with dural graft and intradural dissection of adhesions and reduction by intra pial aspiration or resection of the tonsils is indicated on the MRI aspect of cerebellar tonsils of considerable size totally obstructing the foramen Magnum, the intraoperative finding, through the arachnoid, of the absence of passage of the cerebro-spinal fluid because of the bulging of the cerebellar tonsils.

\section{INTRODUCTION}

The understanding of the pathophysiology of the development of syringomyelia with Chiari malformation formulated in many series $[1,12,20,32,34,38,54,60,67,85]$. explains the use today more and more of cranio-vertebral decompression technique is therefore the common denominator of syringomyelia treatment associated with Chiari I, on the other hand the details of the procedure, the technique of closure of the dura mater, and whether a drainage system should be placed or not in the syringomyelia cavity remains controversial. The maintenance of restored cerebrospinal fluid flow, however, is often problematic.

\section{Keywords syringomyelia, \\ Chiari I, \\ intra pial aspiration of cerebellar tonsils}

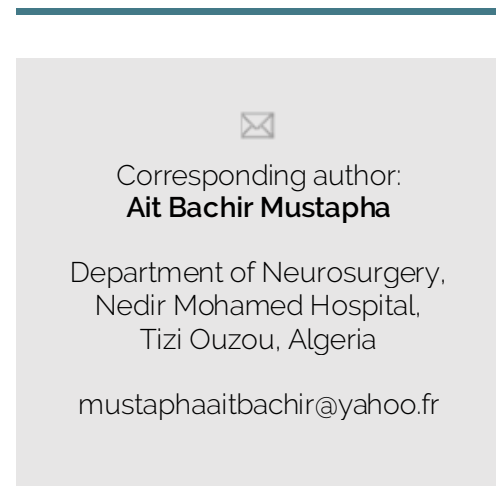

Copyright and usage. This is an Open Access article, distributed under the terms of the Creative commons Attribution Non-Commercial No Derivatives License (https://creativecommons org/licenses/by-nc-nd/4.0/) which permits noncommercial re-use, distribution, and reproduction in any medium, provided the original work is unaltered and is properly cited.

The written permission of the Romanian Society of Neurosurgery must be obtained for commercial re-use or in order to create a derivative work.

ISSN online 2344-4959

(C) Romanian Society of Neurosurgery

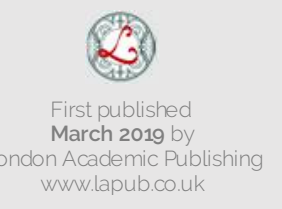


Many different surgical techniques are utilized to treat syringomyelia with Chiari type I malformation, and there is no consensus. Surgical technique may include bony decompression of the posterior fossa with or without duraplasty, arachnoid dissection, or shrinking of the cerebellar tonsils. The goal of any of these operations is to restore adequate cerebro spinal fluid CSF flow at the level of the foramen magnum and reconstruction of the Cisterna magna.

Is the reduction of the volume of the cerebellar tonsils by intra pial aspiration or resection of cerebellar tonsils or finally tonsilar shrinking associated with osteo dural decompresionis the best choice of traitment. we will discuss the results of our series of intra pial aspiration of cerebellar tonsils by comparing it with the different publications cited in the literature and propose our opinion.

\section{Materials And Methods}

\section{Preoperative Population Characteristics}

In our consecutive series of 32/121 patients with cranio-vertebral decompression associated with intrapial aspiration of the cerebellar tonsils or resection of the cerebellar tonsils treated for syringomyelia associated with a Tonsillar herniation (Chiari I malformation) in adults, 10 of them were however excluded from the study for lack of fully exploitable files. Our series therefore includes 22 patients.The mean age of the patients was 30 years. There were 13 female (59\%) and 09 male (40\%) patients.

\section{Preoperative Clinical Symptoms}

Signs and symptoms are summarized in Table I. Sensory disturbances were present in the upper limbs in 59\%. Motor weakness was present together in the upper limbs and in the lower limbs in $90,9 \%$ of patients. Headaches were noted in $45,4 \%$, lower cranial nerves palsy in $13,6 \%$ and Balance disorders or Gait ataxia in 08 cases.

TABLE I. Symptoms/Signs in 22 Patients

\begin{tabular}{|l|l|l|}
\hline Symptom / & $\begin{array}{l}\text { Preoperative } \\
\text { Status } \\
\text { Syringomyelie+Chiaril } \\
\text { (No. of patients) }\end{array}$ & $\begin{array}{l}\text { Postoperative } \\
\text { result (No. of } \\
\text { patients) }\end{array}$ \\
\hline $\begin{array}{l}\text { Weakness \& } \\
\text { muscular } \\
\text { atrophy }\end{array}$ & 20 & 15 \\
\hline
\end{tabular}

\begin{tabular}{|l|l|l|}
\hline $\begin{array}{l}\text { Sensory } \\
\text { disturbance }\end{array}$ & 15 & 13 \\
\hline $\begin{array}{l}\text { Balance } \\
\text { disorders, } \\
\text { Gait } \\
\text { problems or } \\
\text { Gait ataxia }\end{array}$ & 08 & 08 \\
\hline $\begin{array}{l}\text { Pain } \\
\text { headache }\end{array}$ & 10 & 10 \\
\hline $\begin{array}{l}\text { Cranial nerv } \\
\text { dysfonction }\end{array}$ & 03 & 03 \\
\hline
\end{tabular}

The presence or absence of clinical signs was noted in all of these patients and motor disorders were assessed according to Mc Cormick's classification (Table II). All our patients were adults. The distribution by sex shows a female preponderance, which corresponds to what has been reported in some series [57,91,3,93,45,28, 66,79,17, 51,49,14]. Motor disorders were the main symptom of the majority of patients in this series, followed by the sensory disturbances and headaches. We noted ataxia in 08 cases and cranial nerve deficits in 03 cases.

TABLE II. MC Cormick's classification.

\begin{tabular}{ll}
$\begin{array}{l}\text { Functional } \\
\text { grade }\end{array}$ & Clinical prerequisites \\
\hline I & $\begin{array}{l}\text { Intact neurologically, normal ambulation, minimal } \\
\text { dysesthesia }\end{array}$ \\
II & $\begin{array}{l}\text { Mild motor or sensory deficit, functional independence } \\
\text { III }\end{array}$ \\
Moderate deficit, limitation of function, independent \\
IV & $\begin{array}{l}\text { Sexternal aid } \\
\text { dependent }\end{array}$
\end{tabular}

TABLE III. Summary of Preoperative Status of motor disorders and Postoperative results Grade in 22 Patients I: motor disorders were assessed according to Mc Cormick's classification: Pré-opérative stading and after surgery.

\begin{tabular}{|l|l|}
\hline $\begin{array}{l}\text { Pré-opérative Status } \\
\text { Chiaril+Syringomyelie } \\
\text { (No. of patients) }\end{array}$ & $\begin{array}{l}\text { Post opérative Status } \\
\text { Chiaril+Syringomyelie } \\
\text { (No. of patients) }\end{array}$ \\
\hline 09 cases Grade III & $\begin{array}{l}\text { 08 Grade II } \\
\text { (improvement) } \\
01 \text { cases (unchanged) }\end{array}$ \\
\hline 08 cases Grade II & $\begin{array}{l}08 \text { Grade I } \\
\text { (improvement) }\end{array}$ \\
\hline 03 cases Grade IV & Unchanged \\
\hline
\end{tabular}




\begin{tabular}{|l|l|}
\hline 02 cases Grade I & Unchanged \\
\hline 22 & Total \\
\hline
\end{tabular}

\section{Preoperative Imaging}

All patients underwent magnetic resonance imaging (MRI) studies including sagittal and axial spin-echo T1 and T2 sequences. We analyzed the size of the ventricles, studied the anatomy of the occipitovertebral junction, namely the position of the tonsils, the posterior arch of $\mathrm{C} 1$, the height extension of the syringomyelia cavity. Preoperative MRI showed that the syrinx predominantly involved the cervical or the cervicothoracic spinal cord $(28 \%$ and $50 \%$ of the patients respectively) and occupied from $30 \%$ to $80 \%$ of the spinal canal according to the Vaquero's index [81].

Septa were present in $30 \%$ of patients.All patients showed tonsillar herniation reaching the inferior rim of C1. None showed spinal dysraphism or basilar invagination

\section{Surgical technique}

Regarding the surgical technique, all patients of our series of 121 cases were operated in the ventral position which allows the easy visualization of the tonsils, since in the sitting position the tonsils are stretched down under the effect of the universal attraction so they will be less visible than ventral, and also the brainstem and cerebellum have a tendency to migrate downward in the sitting position. In this series, the craniocenvical decompression procedure was chosen based on the different flow of the cerebro spinal fluid dynamics at the cervico vertebral junction. After a small craniectomy, opening the foramen magnum, removing the small lower part of the posterior fossa, and removing the posterior arch of C1. The extent of bone decompression is also important, if the craniectomy is too wide in height, the patient is at risk of ectopy of the cerebellum and recurrence of symptoms. Some authors suggest that the craniectomy should be wide [21] in addition to the craniectomy, Isu [47] is satisfied with the removal of the outer layer of the dura as a treatment for syringomyelia occurring with a Chiari I malformation for him is enough. and others, like us, prefer a small craniectomy in order to avoid the sagging of the cerebellum (cerebellar ptosis), which is sometimes responsible for the patient's death, as reported after a wide craniectomy $[43,83,84]$. Zhang et al. [92] retrospectively analysed 132 patients in a comparison of small and large craniectomy. As noted above, the success rate was $78.2 \%$ in the large craniotomy group, with nearly half of patients developing complications, the most common of which was cerebro spinal fluid fistula (11.5\%), whereas in the small craniotomy group, the success rate was $82.5 \%$ with only three cases of complications. This study demonstrated the superiority of smaller craniotomies.

But according to Ellenbogen [29] a limited craniectomy can lead to inadequate decompression and persistence or recurrence of symptoms, I totally agree with Ellenbogen if we do not realize an intra pial aspiration of cerebellar tonsils. In 2003, Milhorat and Bolognese reported a good result in their experience in tailoring the craniectomy based on the extent of the compressed subarachnoid space on pre-operative magnetic resonance imaging.

We advocate a suboccipital craniectomy limited to enlarging the occipital foramen and allowing both decompression and maintenance of the cerebellum in the posterior fossa. For some authors occipitovertebral decompression alone is enough Di Lorenzo $N$ [26]. then the opening of the dura with keeping the arachnoid intact and an intraoperative exploration that will show if there is a good passage of the cerebro spinal fluid by visualization or observation of the bulge of the arachnoid or not (Figure1). If there is a bulge of the arachnoid it means that there is a good passage of the cerebro spinal fluid so this procedure is sufficient. according to this finding the decision of the realization of the intrapial aspiration of the cerebellar tonsils will be taken. all of the 21 patients in our series have benefited from the intrapial aspiration of the cerebellar tonsils, the extent of intra pial aspiration or resection was ended when the tonsils were reduced and Magendie foramen with the obex of the fourth ventricle are seen.

So even in our therapeutic attitude the decision to use either bone decompression or sub arachnoid manipulation was routinely made intraoperatively, before the dural opening was made. at last duraplasty was also done to all patients using fascia lata graft (Figure2).

During the whole procedure, careful hemostasia isperformed with bipolar forceps under saline irrigationto keep the field bloodless, to prevent adhesions that canbe induced around the spilled blood. 


\section{RESULTS}

Immediate postoperative result and Complications In our series no mortality was seen, this are similar to those reported by $[7,5,16,93]$ who reported no mortality in their series. But we noted, some cases of postoperative complications, such as cerebro spinal fluid leakage (04/22, 18.1\%) who were treated with the use of repeated lumbar puncture with complete closure of the cerebro spinal fluid leakage, three patients $13.6 \%$ have intracranial infection who were treated medically. We have noted, hiccups in one case, who was traited only with the use of a synthetic drug as a tranquilizer, sedative, and antiemetic (chlorpromazine). The most serious complication was aseptic meningitis $(02 / 22,9.09 \%)$ with cerebro spinal fluid leakage $(04 / 22,18.1 \%)$.

Based on the results of this series, headache responds very well to decompression surgery with intra pial aspiration of cerebellar tonsils, on 10 of 22 patients with preoperative headache experienced relief complete immediately after surgery. Motor deficits were present in $20 / 22$ patients, representing $90,9 \%$ of the entire patiens. No motor and sensory aggravation occurred. but the follow-up of the patients shows us that the motor improvement occurs slowly. Other symptoms, such as ataxia in 08 cases and cranial nerve deficits in03 cases, are improved in imediat postoperatively in our series, similar with findings reported by other authors. $[14,17,30,33,37,16]$ series, which adopts the same surgery technique of craniovertebral decompression with tonsillectomy used in this study.

\section{MRI Follow-up}

On the neuro-radiological level, the MRI was performed successively at one month, six months and 12 months then every 02 years, found a normalization of the position of the cerebellar tonsils in all cases with a reconstruction of a new large cisterna magna. The syrinx cavity was clearly or markedly regressed in 09 case, and Slightly regressed in 13 cas.

Syrinx cavity clearly regressed in 09 caseFig2 Figure 3. Preoperative MRI scan reveals syrinx cavity with tonsillar herniation extending below the foramen magnum (Chiaril). Post op Postoperative MRI scan reveals the regression of the syrinx cavity and absence of cerebellar tonsil herniation. (A) Slightly regressed in 13cas Fig3:

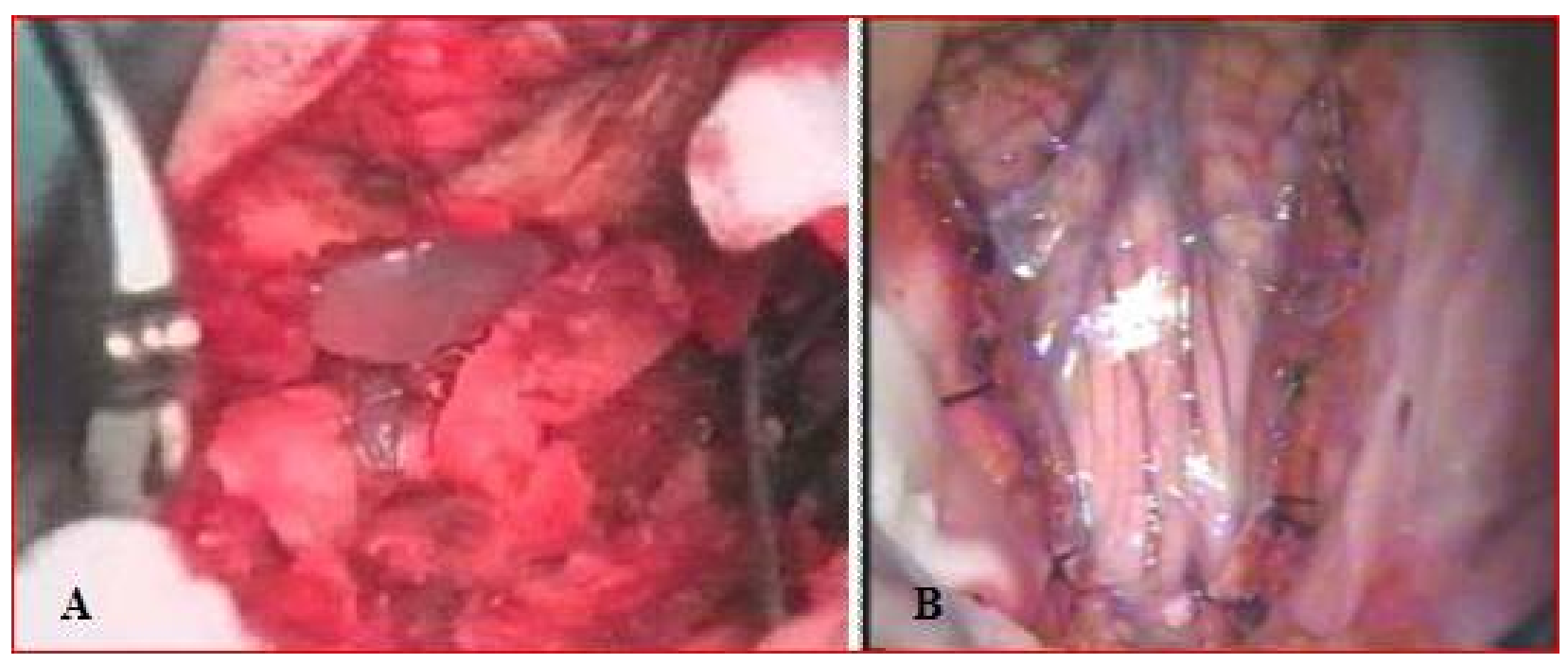

FIGURE 1. Preoperative picture of Dural opening with preservation of intact arachnoid

(A) showed a bulge of the arachnoid which confirms the good passage of the cerebro spinal fluid

(B) shows the large tonsils that occupy a large space and prevent the normal passage of the cerebro spinal fluid 

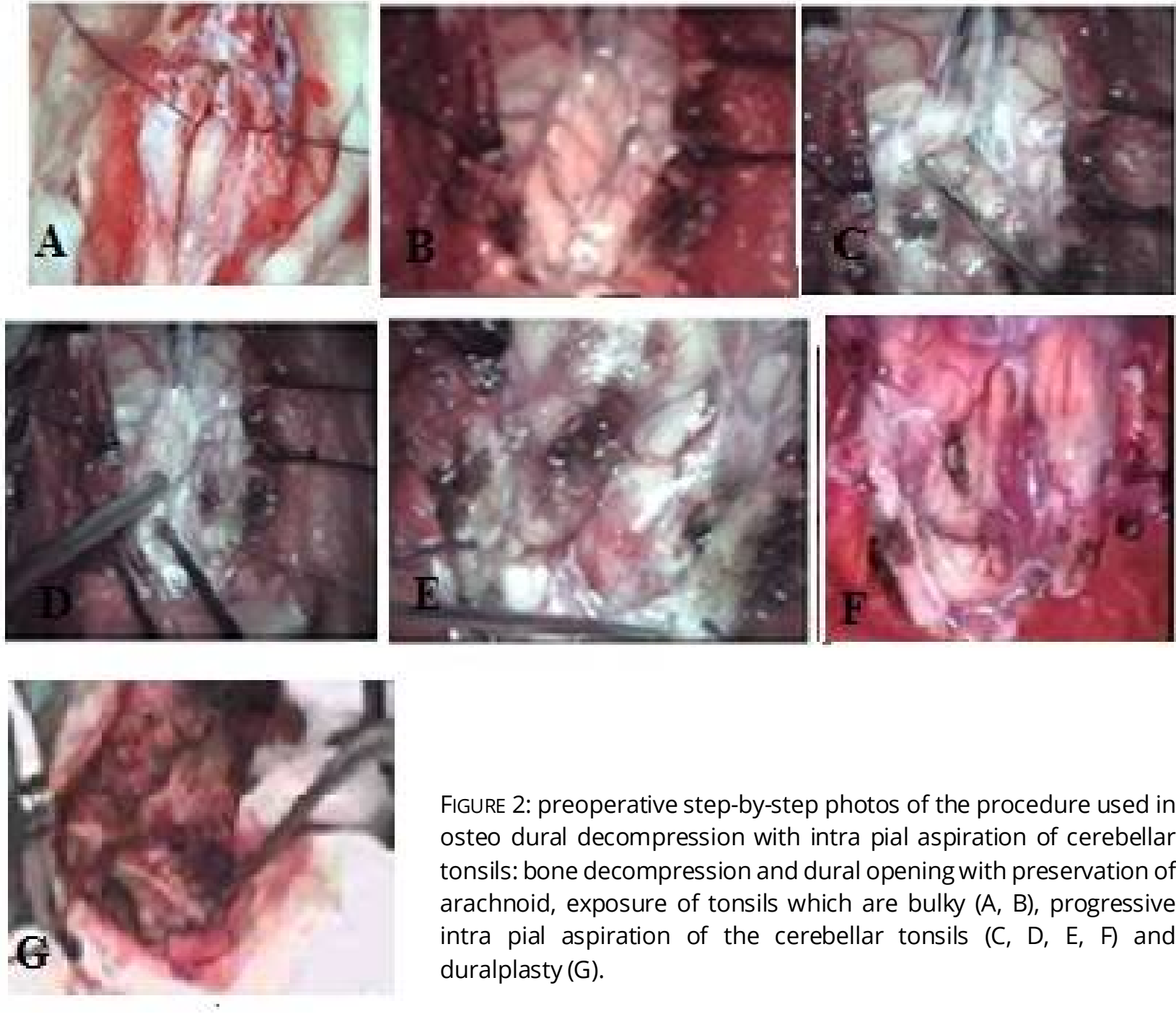

FIGURE 2: preoperative step-by-step photos of the procedure used in osteo dural decompression with intra pial aspiration of cerebellar tonsils: bone decompression and dural opening with preservation of arachnoid, exposure of tonsils which are bulky $(A, B)$, progressive intra pial aspiration of the cerebellar tonsils $(C, D, E, F)$ and duralplasty (G).
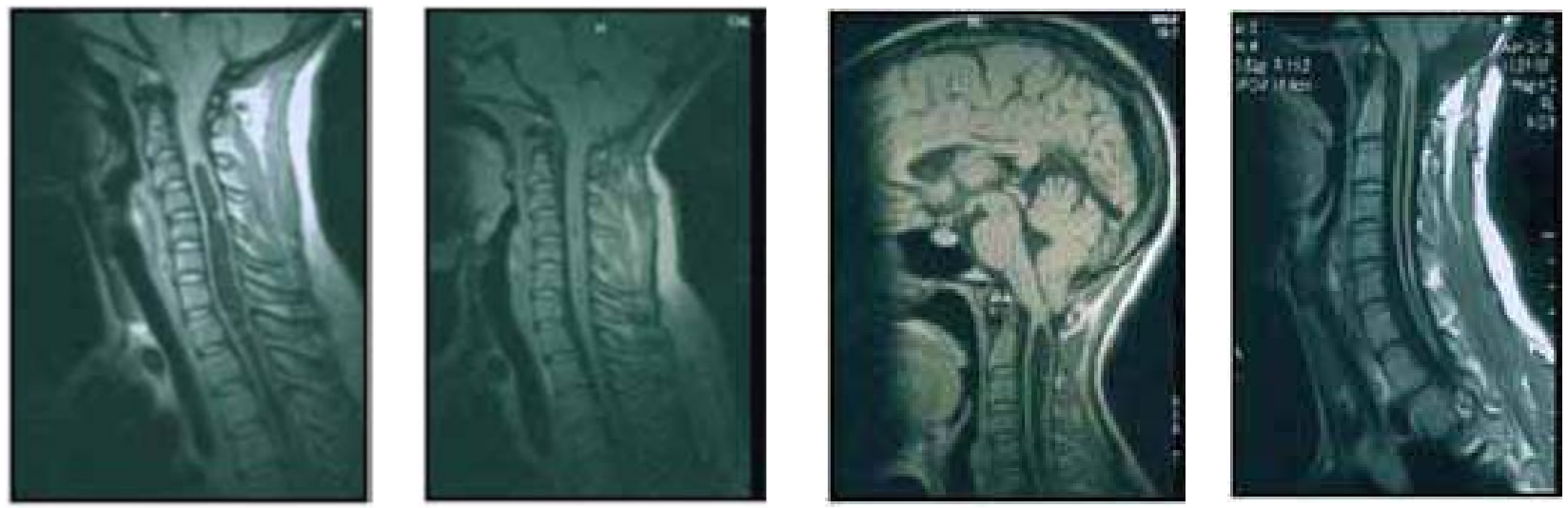

FIGURE 3.

Pre-operative (A) syringomyelia cavity with Chiari I Post-operative(B) clearly regression of the syringomyelia cavity

FIGURE 4.

Syringomyelia cavity pre op with Chiari I (A) Slight postoperative regression of the syringomyelic cavity (B) 
The reoperation was not performed in our series because the result of long-term follow-up of our patients showed an improvement especially on the motor level. among patients who improved $15.79 \%$ remained stable in their initial improvement with an average follow-up over 8 years. These are similar to those in the series of reports on the best prognosis of the literature summarized and reported by Nozar Aghakhani [2].

\section{Literature review}

A literature review was performed with the PubMed search engine of the National Library of Medicine of the National Institutes of Health (http://www.ncbi. nlm.nih.gov/pubmed) and on the research gate site, using the following Keywords "Chiari malformation," "Chiari malformation type I with syringomyelia,"," "posterior fossa decompression with or without duraplasty," and "Craniocervical decompression with duraplasty and cerebellar tonsillectomy." The search was restricted to English-language publications without date limitations.

\section{DISCUSSION}

First, we will say what are the circumstances that led us to opt for this method.

Secondly, we analyse the various publications through the literature, is this method seen our retreat is effective or not, based on the following parameters: the immediate postoperative and the long-term results.

Third is that this method can be proposed in some patients.

To discuss the first issue, as you know that the key point of surgery in syringomyelia with Chiari imalformation is to allow a flow of cerebrospinal fluid at the level of Magendie foramen and foramen magnum. For our part, we have opted for the 22 patients a osteo-dural decompression associated with intra pial aspiration of the cerebellar tonsils for several reasons:

- when the opening of the dura with maintenance of the arachnoid intact and an intraoperative exploration will show us intraoperatively, through the arachnoid, the absence of passage of cerebrospinal fluid due to the large volume of the cerebellar tonsils. As there is no bulge of the arachnoid, this means that there is not a good passage of cerebrospinal fluid in sufficient quantity.
- it has not been demonstrated that the resection of the cerebellar tonsils does not lead to neurological disorders. the function of which is not yet clearly determined.

- Vvsualization or appearance of large cerebellar tonsils and considerable size completely obstructing the foramen Magnum causes neurological disorders.depending on the presence of these 03 parameters, the decision to perform intrapital aspiration of the cerebellar tonsils will be taken.

In our experience, the intra pial aspiration or resection of the tonsils does not lead to a noticeable neurological deficit. according to Asgari $\mathrm{S}$ and al [9] during removal of the cerebellar tonsil, the integrity of the pia mater of the cerebellar tonsil should be preserved to reduce postoperative adhesions, causes aggravation or reappearance of neurological disorders. we take into account the analysis of the literature publication and the study of Arnautovic $A$ [6], and Aghakhani N [2] ,Royo Salvador [71] to evaluate of surgical treatment options in the Chiaril Malformation Type I with syringomyelia and concerning the occurrence of complications during the realization or not of the intrapial aspiration of the cerebellar tonsils, we found that the debate still exists as to whether, once the dura mater is open, arachnoid dissection should be performed or not and if the cerebellar tonsils are resected or retracted or not?. for some neurosurgeons the manipulation of the tonsils can lead in the long term to arachnoid adhesions between the cerebellar tonsils and the dura mater which prevents or hinders the subsequent flow of the cerebro spinal fluid at the foramen Magnum, with worsening of syringomyelia and symptoms according to Asgari S [9]. to avoid this postoperative arachnoiditis Sindou et al [76] and others authors such Hyun Seok L [ 44], Lee HS [56], Oldfield EH [67], Perrini .P[69] advocated or suggested opening of the dura with preservation of the arachnoid membrane and adding duraplasty, and reported favourable results. while in our series on an average of 8 years of follow up, we did not have this type of problem since we did not have any post-operative neurological aggravation in medium and long term (after minimum 1 year of follow-up) which eliminates the eventual arachnoiditis following intra pial aspiration of cerebellar tonsils which is confirmed in the study of Junpeng Ma1[49]and Zuev A.A[93] that the Cerebellar 
tonsillectomy with suboccipital decompression and duraplasty can provide long-time cure for most Chiaril malformation cases, and some authors reported, the good results with this procedure[55, 91]and they have good results. Williams also recommended to remove part of the tonsils to ensure that the pathways are maximally opened. Many papers have supported arachnoid opening and/or tonsillectomy $[5,16,7,93]$. However, a successful surgical outcome (100\% normalization of hindbrain herniation) was reported without arachnoid opening by Heiss et al [39] what was mentioned also by Royo Salvador [71] in his article. Klekamp [52] and Lee HS [56] showed that combined arachnoid pathology was a strong risk factor for symptom recurrence, because any operation undertaken to improve a problem related to arachnoid scarring may create new arachnoid scars, the lesser the extent of dissection and the lesser the contamination of the surgical field with blood, the better the chance of achieving good long-term results

Alden [4] in his article explains that, tonsillar shrinkage or resection has been advocated "as a way to improve the volume mismatch and to increase communication between the fourth ventricle and the spinal compartment". Fisher [30] recommends subpial resection of the cerebellar tonsils, While Batzdorf $U$ [16] and others many neurosurgeons recommend tonsil shrinkage by coagulation or other means. and other authors Gonçalves da Silva J, Arruda J AM [7], Galarza M [30], Raftopoulos C [70] have another way to achieve sub arachnoid manipulation, and claim that this technique improves decompression in the region of the foramen magnum. In his article José Alberto Gonçalves da Silva1and al [22], observed a Blockage of the foramen of Magendie in 55 (52.8\%) patients, mainly caused by the presence of a dense membrane or adhesions between the cerebellar tonsils. In our opinion this is a valid argument for the exploration of the cerebellar tonsil and foramen of Magendie. On the other hand, some of the neurosurgeons $[63,21,39$. leave them intact, performing especially the opening of the fourth ventricle. On the other side, Batzdorf [16] recommends lightly diathermying the pia mater over the surface of the tonsils. for Raftopoulos[70] it is enough just to open the arachnoid and then remove the adhesions.
Secondarily in the past, decompression treatment of the occipito cervical junction has been a dangerous operation, with a significant mortality rate [Di Lorenzo]. With the development of neurosurgery, occipito vertebral decompression has become a relatively low-risk procedure. In our series, there have been no cases of death, or serious infections requiring revision of the wound, Badie et al. [10] retrospectively evaluated 20 cases treated via decompression technique with duraplasty and tonsillectomy. The success rate was $85 \%$, with no mortality. Complications were not described. The 04/22 cases of cerebro spinal fluid leakage in our series is slightly high but if we take all our series of 121 patients who have benefited from occipito cervical decompression with dural plasty, the leak rate of cerebro spinal fluid is similar to that reported in other series $[28,35,40,46,48,49]$. The incidences of CSF-related complications and hydrocephalus in studies about occipito cervical decompression with dural plasty were $4-10 \%$ and 3-4\% respectively [79].

No appearance of a a pseudomeningocel in our series because we use a small suboccipital decompression, this makes it possible to avoid the appearance of a a pseudomeningocel. Recently, Jeffrey $S$ et al [17], performing a small bone decompression report in his article on minimally invasive subpial tonsillectomy for Chiari I decompression significantly reduced the risk of pseudo-meningocele formation.

The incidence of Motor deficits and sensory disorder in our series is higher than in other series $[8,10,68]$. In our series, these motor deficits are improved in 16 out of 22 cases after functional rehabilitation, and remained unchanged in 06cases, we agree with Bălaşa. A, Gherasim.D.N[11 ] who believes that preoperatory longtime neurological deficit is a predictor of poorer outcome, making early surgery. this explains why in our series we had 06 patients who remained unchanged postoperatively and this is probably due to late diagnosis in our patients who only consult at the late stage.

Depreitere et al. [25] retrospectively analysed 22 cases operated used tonsillectomy. On initial followup, 16 patients (76\%) were improved. In late followup, the success rate was $68 \%$. Alfieri et al, reported that surgical decompression with durotomy, arachnoid opening, tonsillar shrinkage, and recreation of the cisterna magna was a safe and effective procedure. Prognosis was excellent, with 
global clinical and radiological improvement in more than $90 \%$ and $80 \%$ of patients, respectively Stanko et al [77] suggested that tonsillar cautery might provide an extra benefit in the resolution of the syrinx compared with bone-only decompression alone or in combination with dural opening. Another previous study reported on 22 adult patients, with the conclusion that sub arachnoid manipilutaion may improve the symptoms in Chiari I malformation [30],In an older study, seven of eight patients who underwent sub arachnoid manipulation showed very good clinical outcomes [36,37] for some neurosurgeons sub arachnoid manipulation are generally accepted as the effective surgical procedures in the treatment of Chiari I malformation $[67,70,72]$, and their effects have been confirmed by clinical practice.

In our series postoperative, MRI scan reveals clearly regression of the syrinx cavity in 09 case, and Slightly regression of the syrinx cavity in 13 cases, based on the Vaquero index and absence of cerebellar tonsil herniation in all cases. Wetjen [82] and co-authors have estimated the rate of syringomyelia resolution by examining the postoperative images in patients after Chiaril malformation decompression. Based on the largest anteroposterior diameter of the syringomyelia, the authors concluded that the median time to greater than 50\% narrowing of the syringomyelia was 3.6 months postoperatively, whereas the mean time was 6.5 months. In a follow-up study by Wu et al. [86], syringomyelia was found to be obviously reduced in all patients examined and completely eliminated in eight patients. in the study of Bao and al [14], the reexamination by MRI in 44 patients showed successful construction of the cis $\neg$ terna magna, with eliminated or obviously reduced syringomyelia in 42 patients. According to de Lotbinière ACJ [58] The tonsillectomy or cerebellar tonsil exeresis proposed by some authors probably adds to the mortality and morbidity rates. It can be an unnecessary and maiming surgical manoeuvre. Alden [4] states that "no neurological deficit has been demonstrated as a result of tonsillar resection; however, the exact function of this structure is largely unknown we agree with Alden effectively, we have practiced it since 1999 and we have not had neurological disorders following their resection including cognitive disorders. taking into consideration that, the role of the cerebellum in learning and cognition began to be considered. In 1997 and 1998 Schmahmann and Sherman [75] named dysfunction of the cerebellums contribution to cognition and behavior the cerebellar cognitive affective syndrome. The posterior lobe of the cerebellum and the vermis contribute to verbal fluency, short-term memory, abstract reasoning, and spatial cognition, functions that may underlie the frequent complaint of "brain fog" in patients the Chiari I malformation. According to Royo Salvador MB [71] the tonsillectomy for syringomyelia with Chiari I, is not indicated, given that no benefit is obtained and it involves an amputation of a part of the cerebellum that can only contribute to sequelae, situations of permanent instability and vertigo.

In our study of clinical presentation in 32 patients with the Chiari I malformation with syringomyelia, we did not consider the psychological and or congenital state during the preoperative clinical examination.

Finally, and generally, the results of this procedure are favourable and differ little between the series. This was confirmed by the present study that the results were good, the complications limited in number in 2005 we presented our comparative study of 40 patients between bone decompression with dural plasty(20 patients) and bone decompression with dural plasty followed by intrapial aspiration of cerebellar tonsils (20 patients) we found that the clinico-radiological results of bone decompression with dural plasty followed by intrapial aspiration of cerebellar tonsils are comparable and sometimes better than the bone decompression with dural plasty [18].

We believe that one of the advantages of arachnoid dissection, in the context of Syringomyelia with Chiari I malformation, is that it allows the surgeon to release the adhesions especially at the foramen of Magendie which could contribute to the obstruction of the cerebro spinal fluid flow from the fourth ventricle to the spinal canal. Whereas the subpial resection of the cerebellar tonsils, especially when they are bulky, we recommend it as a means of improving particularly the passage volume of the cerebro spinal fluid flow and increasing the communication between the fourth ventricle and the spinal cord.

Our experience that patients treated by tonsils resection had a good outcome with no increased operative risk and no additional surgery required 
surgical technique. I totally agree with Arruda and al []in his study Arruda conclude that craniocervical decompression with tonsillectomy and duramater graft proved an effective method for the treatment of Syringomyelia and Chiari malformation.

\section{Limitations}

First, the present study was a retrospective analysis of 22 patients and the small number may have resulted in a lower statistical power. Second a prospective multicentre study with a large and equal number of patients in the occipito cervical decompression and occipito cervical decompression with intra pial aspiration of cerebellar tonsils or tonsillectomy groups might provide sufficient data for an adequate comparison of these 2 techniques to better define the indications and benefits.

\section{CONCLUSIONS}

For the treatment of symptomatic patients, various approaches may be used: bone decompression with dural graft, or bone decompression with dural graft and intradural dissection of adhesions and reduction by intrapial aspiration of the cerebellar tonsils or resection of tonsils because the key point of surgery in syringomyelia with Chiaril malformation is to allow a cerebro spinal fluid flow at the level of foramen of Magendie and foramen magnum. For our part, we have opted for a certain category of patients for osteo-dural decompression associated with subpial resection of the cerebellar tonsils for several reasons: -no neurological disturbance has been demonstrated to result from the intra pial aspiration resection of ectopic cerebellar tonsils,- the function of which is not yet clearly determined - the attribution of the neurological disorders, noted in the pre-surgical phase, to the malformation of Arnold Chiari, the MRI appearance of cerebellar tonsils of considerable size totally obstructing the foramen Magnum. -the intraoperative finding, through the arachnoid, of the absence of passage of the cerebro spinal fluid due to the bulging of the cerebellar tonsils. according to Beecher. J.S[17] the indications for subpial resection of the cerebellar tonsils surgery are the presence of one or more of the following criteria:

1. Karnofsky score of 70 or less secondary to Chiari malformation stereotypic constellation of symptoms
2. An expanding syringomyelia on consecutive MRI scans, syringomyelia cavities in excess of $75 \%$ of the transverse cord diameter on the index MRI, or eccentric appearance of the syringomyelia cavity with intraparenchymal blebs

3. Severe, rapidly progressive neurological deficit

However, it should be acknowledged that this is an observational study and ultimately, we can say that the technique can be used in particular cases. It would be interesting to pay more attention to the effectiveness / inefficiency of the indication of intra pial aspiration of the cerebellar tonsils in the syringimyelie surgery with tonsils herniation (Chiari I malformation).

For these reasons, I believe long-term follow-up, with periodic measures, is required to really understand the success of surgery.

\section{REFERENCES}

1. Aboulker J (1979) La syringomyeÂlie et les liquides intrarachidiens. Neurochirurgie 25: 1 \pm 144

2. Aghakhani N, Parker F, David P, Morar S, Lacroix C, Benoudiba F, Tadie M: Long-term follow-up of Chiarirelated syringomyelia in adults: Analysis of 157 surgically treated cases. Neurosurgery 64: 308-315; discussion 315, 2009

3. Aghakhani N, Parker F, Tadie M: Syringomyelia and Chiari abnormality in the adult. Analysis of the results of a cooperative series of 285 cases [in French]. Neurochirurgie 45:23-36, 1999

4. Alden.T.D, Ojemann.J.G, and Park.T.S, "Surgical treatmentof Chiari I malformation: indications and approaches," Neurosurgical Focus, vol. 11, no. 1, article E2, 2001

5. Alfieri A, Pinna G: Long-term results after posterior fossa decompression in syringomyelia with adult Chiari Type I malformation. J Neurosurg Spine 17(5):381- 387, 2012

6. Arnautovic A, Splavski B, Boop FA, Arnautovic KI. Pediatric and adult Chiari malformation Type I surgical series 19652013: a review of demographics, operative treatment, and outcomes. J Neurosurg Pediatr. 2015; 15:161-77.

7. Arruda JAM, Costa CMC, de Tella Jr OI. Results of the treatment of syringomyelia associated with Chiari malformation: analysis of 60 cases. Arq Neuropsiquiatr 2004; 62:237-244.]

8. Ascho" A, Donauer E, Huwel N, Urban V, Spahn B, Lohlen A, Adams HP (1993) Evaluation of syrinx-surgery. A critical comment on requirements for reliable follow-up-studies. Acta Neurochir (Wien) 123: 224 \pm 225

9. Asgari S, Engelhorn T, Bschor M, Sandalcioglu IE, Stolke D: Surgical prognosis in hindbrain related syringomyelia. ActaNeurol Scand 107:12-21, 2003

10. Badie B, Mendoza D, Batzdorf U: Posterior fossa volume and response to suboccipital decompression in patients 
with Chiari I malformation. Neurosurgery 37:214-218, 1995

11. Bălaşa.A, Gherasim.D.N Our experience in surgical treatment of Chiari Type 1 malformations, Romanian Neurosurgery (2012) XIX 4: 279 - 288

12. Ball MJ, Dayan AD (1972) Pathogenesis of syringomyelia. Lancet 2: 799 \pm 801

13. Bao.C.S, Liu.L,Wang.B, XiaX.G, Gu.Y.J, Li.D.J,Zhan.S.L, Chen. G. L and Yang.F.B , Craniocervical decompression with duraplasty and cerebellar tonsillectomy as treatment for Chiari malformation-I complicated with syringomyelia Genetics and Molecular Research 14 (1): 952-960 (2015)

14. Bao CS, Yang FB, Liu L, Wang B, et al. (2011). Cerebellar tonsilletomy and reconstruction of the cistern magna for treatment of syringomyelia with Chiari malformation. Chin. J. Neuromed. 10: 993-995.

15. Bao C, Yang F, Liu L, Wang B, Li D, Gu Y, et al. Surgical treatment of Chiari I malformation complicated with syringomyelia. Exp Ther Med. 2013; 5(1):333-7.

16. Batzdorf.U, McArthur.D.L,Bentson.J.R, Surgical treatment of Chiari malformation with and without syringomyelia: experience with 177 adult patients, J. Neurosurg. J Neurosurg. 2013 Feb;118(2):232-42

17. Beecher. J.S, Liu.Y,Qi.X,BologneseP.A Minimally invasive subpial tonsillectomy for Chiari I decompression Acta Neurochir (2016) 158:1807-1811

18. Benbouzid T., Ait Bachir M., Berchiche L., Morsli A.Yacoubi B., Sidi Said A. La syringomyélie foraminale. Choix de la procédure chirurgicale. À propos de 40 cas Revue Française de Neurochirurgie, 2005,51, $n^{\circ}$ 5, 523-527.

19. Brugieres $P$, Idy-Peretti I, Iffenecker $C$, et al: CSF flow measurement in syringomyelia. AJNR 21:1785-1792, 2000

20. Catala M. Reflexions d'un neuro-embryologiste. A propos de la syringomyélie dite malformative. Neurochirurgie, Ed Masson, Paris, 1999, 45, suppl. $1: 9-22$

21. Chou YC, Sarkar R, Osuagwu FC, JA. Lazareff . Suboccipital craniotomy in the surgical treatment of Chiari I malformation Childs Nerv Syst (2009) 25:1111-1114

22. Da SilvajA G, Melo LRS; Posterior fossa decompression with tonsillectomy in 104 cases of basilar impression, Chiari malformation and/or syringomyelia; Arq Neuropsiquiatr 2011;69(5):817-823

23. Da Silva. J.A.G, Holanda MMA. Basilar impression, Chiari malformation and syringomyelia. A retrospective study of 53 surgically treated patients. Arq Neuropsiquiatr 2003; 61:368-375.]

24. Deniz B, Uygur Er, Levent G, Kazim Y; Delayed pseudomyelomeningocele: a rare complication after foramen magnum decompression for Chiari malformation; Surgical Neurology 71 (2009) 357-361

25. Depreitere B, Van Calenbergh F, Van Loon J, et al: Posterior fossa decompression in syringomyelia associated with a Chiari malformation: a retrospective analysis of 22 patients. Clin Neurol Neurosurg 102:91-96, 2000

26. Di Lorenzo N, Palma L, Palatinsky E, et al: "Conservative" cranio-cervical decompression in the treatment of
syringomyelia-Chiari I complex. A prospective study of 20 adult cases. Spine 20:2479-2483, 1995

27. Duddy MJ, Williams B. Hindbrain migration after decompression for hindbrain hernia: a quantitative assessment using MRI. Brit J neurosurg $1991 ; 5: 141-152$

28. Dyste GN, Menezes AH, VanGilder JC: Symptomatic Chiari malformations. An analysis of presentation, management, and long-term outcome.J Neurosurg 71:159-168, 1989

29. Ellenbogen RG, Armonda RA, Shaw DW, et al. Toward a rational treatment of Chiari I malformation and syringomyelia. Neurosurg Focus 2000; 8(3): E6. I

30. Fischer EG: Posterior fossa decompression for Chiari I deformity, including resection of the cerebellar tonsils. Childs Nerv Syst 11:625-629, 1995

30. Galarza M, Gazzeri R, Alfieri A, Martínez-Lage JF (2013) B Triple $\mathrm{R}$ tonsillar technique for the management of adult Chiari I malformation: surgical note. Acta Neurochir 155:1195-1201.

32. Gardner WJ, AngelJ (1959) The mechanism of syringomyelia and its surgical correction. Clin Neurosurg 6: 131 140

33. Goel A, Desai K: Surgery for syringomyelia: an analysis based on 163 surgical cases. Acta Neurochir 142:293-302, 2000

34. Greitz D. Unraveling the riddle of syringomyelia. Neurosurg Rev 2006; 29:251- 63; discussion 264 CrossRef Medline

35. Gurbuz M S, Karaaslan.N, Calıskan.T, Unal. E, Erkman M.Z. Comparison of the Surgical Results for ForamenMagnum Decompression with and withoutDuraplasty in Chiari Malformation Type 1 Turk Neurosurg 2015, Vol: 25, No: 3, 419-424

36. Guyotat J, Bret $P$, Mottolese $C$, Jouhanneau E, Abdulrahman M, Lapras C: Chiari I malformation with syringomyelia treated by decompression of the cranio-spinal junction and tonsillectomy. Apropos of 8 cases. Neurochirurgie 43(3):135-41, 1997. (French).

37. Guyotat.J, P. Bret, E. Jouanneau, A.-C. Ricci, and C. Lapras: Syringomyelia Associated with Type I Chiari Malformation. A 21-Year Retrospective Study on 75 Cases Treated by Foramen Magnum. Decompression with a Special Emphasis on the Value of Tonsils Resection Acta Neurochir (Wien) (1998) 140: 745 \pm 754

38. Heiss JD, Patronas N, DeVroom HL, et al: Elucidating the pathophysiology of Syringomyelia. J Neurosurg 91:553562,1999

39. Heiss JD, Suffredini G, Bakhtian KD, Sarntinoranont M, Oldfield EH. Normalization of hindbrain morphology after decompression of Chiari malformation Type I. J Neurosurg. 2012; 117(5):942-6.

40. Heckman KE, Aliaga L, Straus D. et al. Positive and Negative predictors for good outcome after decompressive surgery for Chiari Malformation type I as scored on the Chicago Chiari Outcome Scale. Neurol Res. Sep; 2012 34(7): 694-700

42. Hofmann $E$, Warmuth-Metz $M$, Bendszus $M$, et al: Phasecontrast MR imaging of the cervical CSF and spinal cord: volumetric motion analysis in patients with Chiari I malformation. AJNR 21:151-158, 2000 
43. Holly LT, Batzdorf U: Management of cerebellar ptosis following craniovertebral decompression for Chiari I malformation. J Neurosurg 94:21-26, 2001

44. Hyun Seok L, Sun-Ho L, Kim E, Kim J, Jung-II L, Hyung Jin S et al Surgical results of arachnoid-preserving posterior fossa decompression for Chiari I malformation with associated syringomyelia Journal of Clinical Neuroscience 19 (2012) 557-560

45. Hurth M, Sichez JP (1979) La chirurgie de la charniere craniocervicale. Etude critique à propos de 63 cas d'hydrosyringomyelie operes. Neurochirurgie 25: 114 \pm 128

46. Ilyas M, Frim D, Stine-Reyes R et al. Effects of posterior fossa decompression with and without duraplasty on Chiari malformationassociated Hydromyelia. neurosurg, 2000; 46,6

47. Isu T, Sasaki H, Takamura H, et al. Foramen magnum decompression with removal of the outer layer of the dura as treatment for syringomyelia occurring with Chiari I malformation. Neuro - surgery 1993; 33:845-50

48. Juan C. Alzate, M.D., Karl F. Kothbauer, M.D., George I. Jallo, M.D., And Fred J. Epstein, M.D. Treatment of Chiari type I malformation in patients with and without syringomyelia: a consecutive series of 66 cases Neurosurg Focus 11 (1): Article 3, 2001

49. Junpeng Ma, Chao You, Haifeng Chen, Siqing Huangang , Chengcheng leong ; Cerebellar Tonsillectomy with Suboccipital Decompression and Duraplasty by Small Incision for Chiari I Malformation (with Syringomyelia):Long Term Follow-up of 76 Surgically Treated Cases, Turkish Neurosurgery 2012, Vol: 22, No: 3, 274-279

50. Kalb.S, Luis Perez-Orribo.P.O, Mahan.M, Theodore.N, Nakaji .P , Bristol.R.E. Evaluation of operative procedures for symptomatic outcome after decompression surgery for Chiari type I malformation. Journal of Clinical Neuroscience 19 (2012) 1268-1272

51. Klekamp J, Surgical Treatment of Chiari I MalformationAnalysis of Intraoperative Findings, Complications, and Outcome for 371 Foramen Magnum Decompressions, Neurosurgery 71:365-380, 2012

52. KlekampJ, laconettag, Batzdorf.U, Samii.M. Syringomyelia associated with foramen magnum arachnoiditis J Neurosurg (Spine 3) 97:317-322, 2002

53. Klekamp J, Samii M. Syringomyelia-Diagnosis and Treatment. Heidelberg, Germany: Springer Verlag; 2001

54. Koyanagi I, Houkin K. Pathogenesis of syringomyelia associated with Chiari type I malformations: review of evidences and proposal of a new hypothesis. Neurosurg Rev 2010; 33:271- 84; discussion 284-85 CrossRef Medline

55. Lazareff JA, Galarza M, Gravori T, Spinks TJ: Tonsillectomy without craniectomy for the management of infantile Chiari I malformation.J Neurosurg 97:1018-1022, 2002

56. Lee HS, Lee SH, Kim ES, Kim JS, Lee JI, Shin HJ, Eoh W (2012) Surgical results of arachnoid-preserving posterior fossa decompression for Chiari I malformation with associated syringomyelia. J Clin Neurosci 19(4):557-560
57. Levy WJ, Mason L, Hahn JF Chiari malformation presenting in adults: a surgical experience in 127 cases. neurosurgery, 1983; 12: 377-90

58. Lotbinière $A C$. Historical considerations. In Anson JA, Benzel EC, Awad IA (eds). Neurosurgical topics: syringomyelia and Chiari malformations. Illinois: American Association of Neurologic Surgeons, 1997:1-26.

59. Menezes AH (2011) Current opinions for treatment of symptomatic hindbrain herniation or Chiari type I malformation. World Neurosurg 75:226-228,

60. Milhorat TH, Capocelli ALJr, Anzil AP, et al: Pathological basis of spinal cord cavitation in syringomyelia: analysis of 105 autopsy cases. J Neurosurg 82:802-812, 1995

61. Milhorat TH, Chou MW, Trinidad EM, et al: Chiari I malformation redefined: clinical and radiographic findings for 364 symptomatic patients. Neurosurgery 44:10051017, 1999

62. Milhorat TH, Johnson WD, Miller Jl, et al: Surgical treatment of syringomyelia based on magnetic resonance imaging. Neurosurgery 31:231-245, 1992

63. Milhorat TH, Bolognese PA (2003) Tailored operative technique for Chiari type I malformation using intraoperative color Doppler ultrasonography. Neurosurgery 53:899-905 discussion905-896

64. Misao N, Hiroaki S, Akira H, Naruhiko N, Yuichi I: Pathogenesis of Chiari malformation: A morphometric study of the posterior cranial fossa. J Neurosurg 16:14491454, 2009

65. Momen M Almamoun, MD., Walid KAbouzeid, MD. Efficacy and Safety of Duraplasty in Chiari Malformation Type-I Patients Associated with Syringomyelia Egy Spine J Volume 17 -January 2016.

66. Munshi I, Frim D, Stine-Reyes R, et al: Effects of posterior fossa decompression with and without duroplasty on Chiari malformation-associated hydromyelia. Neurosurgery 46: 1384-1390, 2000

67. Oldfield EH, Muraszko K, Shawker TH, et al: Pathophysiology of syringomyelia associated with Chiari I malformation of the cerebellar tonsils. Implications for diagnosis and treatment. J Neurosurg 80:3-15, 1994

68. Paul KS, Lye RH, Strang FA, et al: Arnold-Chiari malformation. Review of 71 cases.J Neurosurg 58:183-187, 1983

69. Perrini. P, Benedetto.N,Tenenbaum.R,Di Lorenzo.N, Extraarachnoidal craniocervical decompression for syringomyelia associated with Chiari I malformation inadults: technique assessment, Acta Neurochir. 149 (2007) 1015-1022,

70. Raftopoulos C, Sanchez A, Matos C, Baleriaux D, Bank WO, Brotchij. Hydrosyringomyelia-Chiari 1 complex. Prospective evaluation of a modified foramen magnum decompression procedure: preliminary results. Neurol surg 1993; 39:163-9

71. Royo Salvador MB. Filum System ${ }^{\circledR}$ A Brief Guide. Chiari \& Scoliosis \& Syringomyelia Foundation. 2017.].

72. Rocque BG, Oakes WJ (2015) Surgical treatment of Chiari I malformation. Neurosurg Clin N Am 26:527-531 
73. Sakamoto $H$, Nishikawa $M$, Hakuba $A$, et al: Expansive suboccipital cranioplasty for the treatment of syringomyelia associated with Chiari malformation. Acta Neurochir 141:949-961, 1999

74. Santamarta D, Kusak ME, de Campos JM, et al: Increased cerebrospinal fluid flow through the foramen of Magendie after decompression for Chiari I malformation. J Neurol Neurosurg Psychiatry 66:799, 1999

75. Schmahmann JD, Sherman JC. The cerebellar cognitive affective syndrome. Brain 1998; 121 (Pt 4): 561-579

76. Sindou M, Chávez-Machuca J, Hashish H. Craniocervical decompression for Chiari type I-malformation, adding extreme lateral foramen magnum opening and expansile duraplasty with arachnoid preservation. Technique and long-term functional results in 44 consecutive adult cases-comparison with literature data. Acta Neurochir (Wien). 2002;144(10):1005-1019

77. Stanko KM, Lee YM, RiosJ et al (2015) Improvement of syrinx resolution after tonsillar cautery in pediatric patients with Chiari type I malformation. J Neurosurg Pediatr 30:1-8

78. Stovner LJ, Rinck P: Syringomyelia in Chiari malformation: relation to extent of cerebellar tissue herniation. Neurosurgery 31:913-917, 1992

79. Tetsuryu $M_{\text {" }}$ Yasuo A, Takaomi T, Seiichiro E, Kentaro C,Yoshikazu O, Takakazu K Reevaluation of foramen magnum decompression with dura left open for Chiari I malformation Interdisciplinary Neurosurgery 10 (2017) 150-154

80. Udani V, Holly LT, Chow D, Batzdorf U. Posterior fossa reconstruction using titanium plate for the treatment of cerebellar ptosis after decompression for Chiari malformation. World Neurosurg. 2014; 81(5-6):836-41.

81. Vaquero J, Martínez R, Arias A. Syringomyelia-Chiari complex: magnetic resonance imaging and clinical evaluation of surgical treatment. J Neurosurg. 1990 Jul;73(1):64-8.

82. Wetjen NM, Heiss JD, Oldfield EH. Time course of syringomyelia resolution following decompression of Chiari malformation Type I. J Neurosurg Pediatr. 2008; 1:118-123.

83. Williams B. Surgery for hindbrain related syringomyelia. In Advances and technical standarts in neurosurgery, vol 20, Berlin, Springer Verlag, 1993; 108-164
84. Williams, B(Chapter in book). Management Schemes for Syringomyelia: Surgical Indications and Nonsurgical Management. In: Anson J, Benzel EC, Awad I, eds. Syringomyelia and The Chiari Malformation (Neurosurgical Topic Vol 26), USA: Thieme/The American Association of Neurological Surgeons. 1997: pp 125-143

85. Williams B: A critical appraisal of posterior fossa surgery for communicating syringomyelia. Brain 101:223-250, 1978

86. Wu HB, Chen J and Li AM (2010). Reconstruction of the cistern magna for treatment of syringomyelia with Chiari I malformation. Chin. J. Pract Nerv. Dis. 13: 89-90.

87. Yamazaki $Y$, Tachibana S, Takano $M$, et al: Clinical and neuroimaging features of Chiari type I malformations with and without associated syringomyelia. Neurol Med Chir 38:541-547, 1998

88. Yilmaz A, Kanat A, Musluman AM, ET AL. When is duraplasty required in the surgical treatment of Chiari malformation type I based on tonsillar descending grading scale? World Neurosurg. 2011;75(2):307-313.

89. Yundt KD, Park TS, Tantuwaya VS, et al: Posterior fossa decompression without duraplasty in infants and young children for treatment of Chiari malformation and achondroplasia. Pediatr Neurosurg 25:221-226, 1996

90. Zamel K, Galloway G, Kosnik EJ, et al. Intraoperative neurophysiologic monitoring in 80 patients with Chiari I malformation: role of duraplasty. J Clin Neurophysiol 2009; 26:70-5.

91. Zhang ZQ, Chen YQ, Chen YA, Wu X, Wang YB, Li XG. Chiari I malformation associated with syringomyelia: a retrospective study of 316 surgically treated patients. Spinal Cord. 2008;46(5):358-363

92. Zhang Y, Zhang N, Qiu H, ZhouJ, Li P, Ren M, et al. An efficacy analysis of posterior fossa decompression techniques in the treatment of Chiari malfor $\neg$ mation with associated syringomyelia. J Clin Neurosci. 2011; 18(10):1346-9.

93. Zuev a.a, Pedyash n.v, Epifanov d.s, Kostenko g.v: Results of Surgical Treatment of Syringomyelia Associated with Chiari 1 Malformation. An Analysis of 125 Cases. Pirogov National Medical Surgical Center, Moscow, Russia. problems of neurosurgery named after n.n. burdenko 1, 2016 